\title{
HIV/HCV-Coinfection: Which Role CAn NeW Antiretrovirals SUCH AS INTEGRASE INHIBITORS Play?
}

\author{
Martin Vogel ${ }^{1}$, Mark Nelson² \\ ${ }^{1}$ Department of Internal Medicine I, Bonn University, Germany. \\ ${ }^{2}$ Department of HIV Medicine, Chelsea and Westminster Hospital, London, UK
}

\begin{abstract}
End-stage liver disease has become one of the most frequent causes of death in HIV/HCV-coinfected patients. The role of new antiretrovirals in the progression of liver fibrosis has yet to be defined. However with significant toxicities and drug-to-drug interactions of nucleoside reverse transcriptase inhibitors in combination with ribavirin, with drug to drug interaction of HIV protease inhibitors with HCV protease inhibitors and calcineurin-inhibitors, new antiretrovirals lacking these interactions represent attractive alternatives in the setting of anti-HCV therapy or post liver transplantation. In the following review we want to focus on the new class of HIV integrase inhibitors and discuss present data with regard to special issues of HIV and HCV co-infection.
\end{abstract}

Key words: integrase inhibitor, raltegravir, elvitegravir, $\mathrm{HIV}, \mathrm{HCV}$, liver disease

\section{INTRODUCTION}

With the introduction of HAART and the rapid decline of AIDS-associated mortality other comorbidities such as chronic liver disease have become main drivers for morbidity and mortality [1]. In HCV/HIV co-infected individuals sequelae of end-stage liver disease have become the most frequent non-AIDS cause of death [2]. Whereas the overall effect of HAART has been shown to be beneficial on liver fibrosis progression, probably by suppressing HIV replication and immune activation, recent data suggest that long-time exposure and accumulating drug toxicity [3], and exposure to certain antiretrovirals such as didanosine [47] may adversely effect the risk for liver fibrosis progression and liver related death.

Problems may also be encountered during the concomitant treatment of chronic hepatitis $\mathrm{C}$ infection with pegylated interferon and ribavirin combination therapy and antiretroviral therapy for HIV. Nucleoside analogues have been shown to interact with ribavirin leading to enhanced toxicity of either the nucleoside analogue or ribavirin or diminished treatment response rates probably on the basis of drug-to-drug interactions leading to decreased amounts of the active compound of ribavirin [8]. In addition, the use of specifically targeted antiretroviral therapies against he- patitis C (Stat-C) in HIV-infected populations is at present limited due to expected severe drug-to-drug interactions between inhibitors of the HIV- and HCVprotease.

End-stage liver disease compromises the metabolic capacity of the liver and can lead to toxic overdosing of antiretroviral drugs if proper dose adjustments are ignored [9-11]. Patients in need for liver transplantation encounter significant drug-to-drug interactions with protease inhibitors and immunosuppressants complicating dosing and therapeutic drug monitoring of calcineurin inhibitors and sirolimus [12-14]. New drugs with different metabolic pathways and thus less potential for drug-to-drug interactions and liver-function independent dosing would clearly be an asset in the clinical management of these patient collectives.

In the following review we want to address different aspects of HAART in the context of $\mathrm{HIV} / \mathrm{HCV}$ co-infection with particular focus on the new drug class of integrase inhibitors.

\section{HePATOTOXICITY}

Preexisting liver disease and raised ALT/AST values have consistently been found to be a predictor of HAART-related hepatotoxicity in cohort and clinical studies [15]. Even though patients co-infected with hepatitis are at significantly increased risk for hepatotoxicity, the benefits of immune reconstitution by far outweigh the potential risk for hepatotoxicity under HAART and HAART rarely needs to be stopped as a result of liver related injury.

Hepatic events have been described at similar frequency in clinical trials and cohorts. Some drugs have however been found to be associated with an increased risk of hepatotoxic events, and these are stavudine, didanosine, nevirapine and full dose ritonavir [16-19]. Nevirapine asscociated liver toxicity may have been overestimated in the past due to an enhanced risk of hypersensitivity reaction in case nevirapine is started in treatment naïve females with a CD4-count $>250 / \mu \mathrm{l}$ or in males with a CD4-count $>$ $400 / \mu 1[20,21]$, though caution is still warranted in patients with hepatitis coinfection and in particular those with advanced fibrosis and cirrhosis [9, 22, 23] and fatal cases of liver failure have been observed [2427]. Drugs with increased risk of hepatotoxicity 
should if possible be avoided or used cautiously in patients with chronic hepatitis $\mathrm{C}$ co-infection as this patient population per se is at increased risk for elevated liver transaminases elevation after start of HAART.

\section{MitochONDRIAL TOXICITY}

Nucleoside analogues are designed to be incorporated into viral nucleic acids and act as chain terminators thus inhibiting efficient viral replication. The toxicity of these drugs is caused by inhibiting the human mitochondrial DNA polymerase gamma, an enzyme physiologically required for mtDNA replication [28]. Nucleoside reverse transcriptase inhibitor induced depletion of mtDNA leads to the impairment of fatty acid oxidation and microvesicular steatosis of the liver. Moreover, disruption of the mitochondrial respiratory chain may indirectly have a cytopathic effect on the hepatocyte and fulminant hepatic failure associated with lactic acidosis has been described as an adverse event under NRTI-containing HAART [29-31]. Fortunately, hepatic failure with lactic acidosis rarely occurs and the incidence rate is estimated to be $<0.01 \%$ of patients receiving NRTI. In vitro mitochondrial toxicity varies between compounds. Of the NRTIs zalcitabine, stavudine and didanosine exert the highest inhibition of polymerase gamma whereas the degree of inhibition by emtricitabine, lamivudine, tenofovir, and abacavir is low. These data mirror clinical experience where most cases of lactic acidosis and severe hepatotoxicity were observed in conjunction with stavudine, zalcitabine or didanosine containing regimens [32-35]. The use of didanosine and stavudine in patients with hepatitis co-infection should therefore be avoided if possible.

Within the class of integrase inhibitors, biochemical studies are available for raltegravir demonstrating that raltegravir is highly selective for HIV integrase and bound $>1,000$-fold selectively for integrase compared with the human polymerase gamma [36]. Based on these in-vitro studies no mitochondrial toxicity is to be expected and raltegravir may represent a suitable alternative in the context of a nucleoside free HAART when other nucleosides or nucleotides are not a therapeutic option.

\section{Hepatosteatosis}

The use of antiretroviral agents, in particular protease inhibitors and NRTI, have frequently been associated with the development of insulin resistance, triglyceride plus or minus cholesterol elevations and a lipodystrophy syndrome [37]. All these entities have been associated with non-alcoholic fatty liver disease and its complications [38]. Evidence for increased hepatosteatosis under particular antiretroviral agents has been limited to NRTIs and in particular stavudine thus far [39, 40]. Though there is theoretical rationale that protease inhibitors may also enhance the risk for hepatic steatosis as they have been associated with dyslipidemia and insulin resistance, no study has yet shown a specific risk of protease inhibitors on hepatic steatosis. Whether new antiretroviral drugs with improved metabolic profile, such as raltegravir [41, 42], may prevent or ameliorate hepatosteatosis has yet to be determined.

\section{Hepatic SAFEty of Integrase InHibitors in Hepatitis Co-infected Patients}

Of the current integrase inhibitors in clinical development, data on HCV co-infected patients is currently only available for the already licensed integrase inhibitor raltegravir. In treatment naive patients, protocol 021 of the STARTMRK study [42], $7 \%$ of patients enrolled in this trial were either hepatitis B or C coinfected. Grade 3 or 4 laboratory abnormalities occurred at similar frequencies within the efavirenz based arm and the raltegravir based arm with regard to ALT, AST, or alkaline phosphatase or total bilirubin elevations (Table 1).

Data on the hepatic safety in hepatitis co-infected patients is available at present from the phase III studies [43-45]. Patients with chronic active hepatitis B and/or hepatitis C co-infection were permitted to enroll provided that the liver function tests, i.e. AST, ALT and alkaline phosphatase, did not exceed five times the upper limit of normal. Overall 113 of 699 patients were either co-infected with hepatitis B or hepatitis $C$ or both $(16.2 \%)$. In general, the safety profile of raltegravir in patients with hepatitis $\mathrm{B}$ and/or hepatitis $C$ coinfection was similar to that in patients without hepatitis B and/or hepatitis C coinfection. Liver related laboratory abnormalities occurred at similar frequency within raltegravir and optimized background treatment arms [43, 44]. As expected, in hepatitis co-infected patients [45] elevations of AST, ALT or total bilirubin were more often found, in $31 \%$, $31 \%$, and $16 \%$ of patients, respectively, as compared to $9 \%, 8 \%$, and $8 \%$ of all other raltegravir-treated subjects (Fig. 1). Two recent investigator initiated stud-

Table 1. Hepatic grade 3 / 4 laboratory abnormalities in ART naïve patients on Raltegravir or Efavirenz, both in combination with TDF/FTC.

\begin{tabular}{lccc}
\hline Adverse Event & $\begin{array}{c}\text { Toxicity Criteria } \\
\text { Grade } \mathbf{3} \text { or } \mathbf{4}\end{array}$ & $\begin{array}{c}\text { Raltegravir } \\
\mathbf{n}=\mathbf{2 8 1}\end{array}$ & $\begin{array}{c}\text { Efavirenz } \\
\mathbf{n}=\mathbf{2 8 2}\end{array}$ \\
\hline Total bilirubin & $>2.5 \times \mathrm{ULN}$ & $2(0.7)$ & $0(0.0)$ \\
Alkaline phosphatase & $>5 \times \mathrm{ULN}$ & $0(0.0)$ & $2(0.8)$ \\
AST & $>5 \times \mathrm{ULN}$ & $6(2.1)$ & $5(1.8)$ \\
ALT & $>5 \times \mathrm{ULN}$ & $5(1.8)$ & $6(2.1)$ \\
\hline
\end{tabular}

AST aspartate amino transferase; AP alkaline phosphatase; ALT alanine aminotransferase; ULN upper limit of normal 


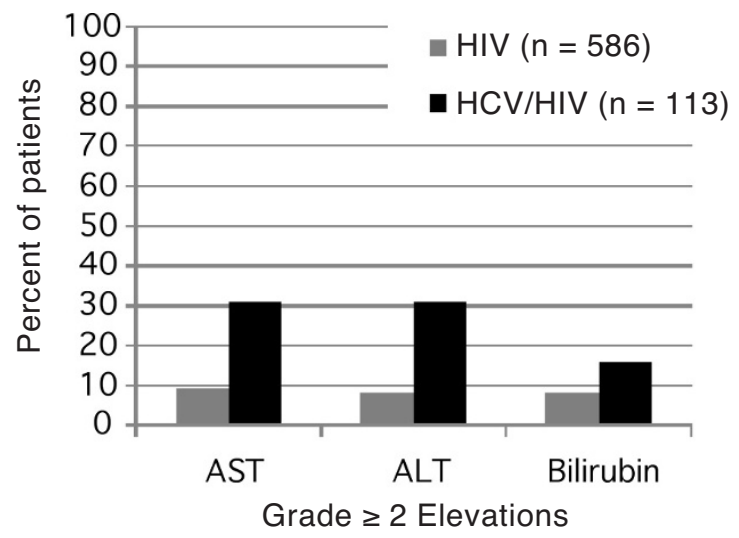

AST aspartate aminotransferase; ALT alanine aminotransferase

Fig. 1. Hepatic laboratory abnormalities in phase III studies of raltegravir in HIV and HCV/HIV co-infected patients.

ies from Spain and the UK have also reviewed the hepatic safety of raltegravir in HCV co-infected patients. A single center study from Spain evaluated 218 HIVpositive patients who had received raltegravir as part of HAART [46]. Apart from being part of a rescue regimen, raltegravir was prescribed in $59 \%$ of patients because of poor tolerance or side effects with an otherwise virologically suppressive regimen. Ninetytwo $(42 \%)$ were HCV positive. In this study any grade of ALT elevation was observed in $8 \%$ of $\mathrm{HIV}$ and $25 \%$ of $\mathrm{HCV} / \mathrm{HIV}$ co-infected patients $(\mathrm{p}<0.001$ ). Only three ALT elevations grade 3 or 4 were observed among HCV-positive patients, however all were considered not related to raltegravir. Among HCV-negative patients no grade 3 or 4 ALT elevation was observed.

In a UK study 13 patients co-infected with HIV and HCV were switched from a PI $(\mathrm{n}=7$ ), NNRTI ( $\mathrm{n}$ $=4)$, or NRTI only $(n=2)$ to a raltegravir based HAART [47]. The mean ALT at baseline and three months was $247 \mathrm{U} / 1$ and $176 \mathrm{U} / 1$, respectively. Eight patients experienced sustained improvements in the ALT at three months, though the reduction in mean ALT from baseline to three months after commencing raltegravir was not statistically significant $(p=0.1)$.

In summary raltegravir appears to have a favorable hepatic safety profile and increased rates of ALT elevations among hepatitis co-infected patients are similar to those observed with other recent new drugs in other clinical trials and cohorts.

\section{EFFECT OF HAART ON LIVER FIBROSIS Progression IN Chronic Hepatitis}

Likely due to increasing and maintaining high CD4cell counts as well as reducing HIV-associated immune activation HAART has been associated with reduced progression of liver fibrosis in $\mathrm{HCV}$-coinfected patients and currently the European and International AIDS Clinical Society guidelines recommend early treatment initiation of antiretroviral therapy in HCV co-infected patients [8]. In fact, whereas treatment initiation is recommended in $\mathrm{HIV}$-monoinfected patients with a CD4 helper cell count $<350 / \mu$, regardless of the level of HIV-RNA, treatment in patients with HCV co-infection is recommended at a CD4 cell count between 350-500/ $\mu$ l.

One of the main reasons for this recommendation is summarized in a recent review of trials investigating into the effect of antiretroviral therapy on the progression of liver fibrosis in HCV- and HIV-coinfected patients [3]. Here it was shown that HAART might attenuate the progression of liver fibrosis. Although the influence of HAART did not reach statistical significance in this meta-regression analysis, the risk for cirrhosis was estimated to be lower in patients on HAART (risk ratio $1,72,95 \%$ CI $1,06-2,80$ ) than in patients without HAART (risk ratio 2,49, $95 \%$ CI 1,81-3,42), each of the groups compared with HCVmonoinfected patients. In part the lack of significant influence of HAART in this meta-analysis may be explained by the fact that only limited studies with data on HAART were available, that among the HAART studies only $74 \%$ of patients were actually on HAART and that HAART was not always effective in terms of maximally suppressed HIV-RNA. Moreover, patients had been on HAART for rather short periods of time so that long-term beneficial effects of HAART may have been missed.

One of the largest cross-sectional biopsy studies on 656 patients showed overall a similar fibrosis progression rate among HCV-monoinfected compared with $\mathrm{HIV} / \mathrm{HCV}$-coinfected patients [48]. However, dividing $\mathrm{HCV} / \mathrm{HIV}$-coinfected patients according to their respective CD4 cell count and level of HIV RNA, Bräu et al. showed that viremic patients had enhanced fibrosis progression compared to aviremic $\mathrm{HCV} / \mathrm{HIV}$ coinfected and HCV-monoinfected patients. Moreover, the level of viremia had the strongest influence on the fibrosis progression; although aviremic patients had a fibrosis progression rate of 0.122 Ishak fibrosis units per year, patients with a viral load between 400-99,000 copies/ $\mathrm{ml}$ had a progression rate of 0.145 Ishak fibrosis units per year and lastly, patients with an HIV RNA of more than 100,000 copies/ml had a progression rate of 0.196 Ishak fibrosis units per year. An accelerated fibrosis progression rate in HIV viremic patients was seen with CD4 cellcounts $<500$ $/ \mu$ l compared with aviremic patients $(0.162$ vs. 0.123 , $\mathrm{p}=0.005)$ but not with CD4 cellcounts $>500 / \mu \mathrm{l}$ (0.118 vs. $0.121, \mathrm{p}=0.89$ ).

That these findings indeed translate into clinical end-points has been shown impressively by Pineda and colleagues [49]. During prospective follow-up of 1.011 HIV/HCV co-infected hepatic decompensation was observed in 60 and liver-related death in $30 \mathrm{pa}$ tients. Among the factors independently associated with the occurrence of hepatic decompensation were a CD 4 cell count gain lower than 100 cells/ $\mu$ l and less than $60 \%$ of the follow-up with undetectable HIV viral load. Vice versa Bruno and colleagues were able to show that initiating HAART after a first hepatic decompensation significantly reduced the risk for a new hepatic decompensation and liver- related death [50].

Data on individual agents of antiretroviral therapy and their risk on liver fibrosis progression, for the most part, is not uniform across studies, though more consistent data have been gathered on a possible nega- 
tive impact of didanosine on the progression of liver fibrosis [4-7]. New antiretrovirals may offer improved benefits on liver fibrosis progression due to better long-term hepatic safety profiles. Also direct antifibrotic effects of the antiretroviral drug, as have been postulated for the CCR 5 inhibitors based on in-vitro data and genetic studies on CCR 5 polymorphisms [51, 52], , may turn out to be of additional benefit to the patient. Due to the recent licensure of raltegravir, and with elvitegravir and S/GSK1349572 still in clinical development, few long-term follow-up is available and at present there is no information whether integrase inhibitors may outperform other antiretrovirals with regard to liver fibrosis progression.

\section{HAART AND ANTI-HCV THERAPY}

Treatment of hepatitis C with pegylated interferon and ribavirin in patients on antiretroviral therapy may lead to enhanced toxicity of either ribavirin or antiretroviral drugs or lack of efficacy due to drug-to-drug interactions between ribavirin and antiretroviral drugs. Due to drug-to-drug interactions the levels of didanosine in combination with ribavirin are enhanced and severe life-threatening cases of pancreatitis have been observed under treatment of ribavirin together with didanosine [53]. The use of didanosine in combination with ribavirin is thus contraindicated. Similarly, the concomitant use of zidovudine and ribavirin has been shown to increase the risk for anemia [54] and stavudine the risk of lipoatrophy [55] and both should be avoided if possible. Recently patients on concomitant abacavir showed lower sustained virological response rates than patients who were not on abavavir [56, 57]. Intracellular drug-to-drug interactions of ribavirin and abacavir, competing for the same metabolism pathway, are hypothesized to be responsible for this phenomenon, yielding decreased amounts of biologically active ribavirin. More recent analyses suggest that this drugto-drug interaction can be overcome by adequate ribavirin dosage, i.e. current recommended weight-adapted daily doses of 1000 or $1200 \mathrm{mg}$, so that overall abacavir-based HAART may be continued if weightbased ribavirin is given to the patient $[58,59]$. Due to these interactions a nucleotide based or nucleosidesparing regimen may be a reasonable option for patients undergoing pegylated interferon/ribavirin therapy. Indeed, a recent German multicenter study suggested that nucleoside-free HAART may result in better treatment responses compared to patients who continued their standard HAART [60].

Integrase inhibitors constitute a different chemical class of compounds, i.e. unlike ribavirin or NRTIs they do not belong to the class of nucleoside analogues and thus, interactions between integrase inhibitors and ribavirin are are not expected. Clinical trials have to show whether a switch from nucleoside analogues to integrase inhibitors, both as part of HAART, for the duration of anti-HCV therapy may be an option to reduce toxicity and perhaps even increase treatment response rates.

With the development of Stat-C and in particular the most advanced agents in clinical development, telaprevir and boceprevir, new anti-HCV drugs are be- coming available for patients with chronic hepatitis C. Telaprevir and boceprevir both have shown very promising results for patients with $\mathrm{HCV}$ genotype 1 infections who are naïve to anti-HCV therapy or who have failed prior standard of care therapy with pegylated interferon and ribavirin. However, in HIV-infected patients, significant drug-to-drug interactions between boceprevir or telaprevir with HIV protease inhibitors are expected, and will further complicate treatment with these agents.

New antiretroviral agents such as the integrase inhibitors raltegravir and S/GSK1349572, both of which have not shown any significant inhibition of CYP3A $[61,62]$, are not expected to show any significant drugto-drug interactions with the HCV protease inhibitors boceprevir or telaprevir. Integrase inhibitors may offer attractive treatment options, i.e. switching from a protease inhibitor based HAART to an integrase inhibitor based HAART, for HCV/HIV co-infected patients undergoing treatment for chronic hepatitis $\mathrm{C}$ with telaprevir or boceprevir. Clinical data on switch-strategies similar to the one suggested are still lacking. Moreover, based on the results of the SWITCHMRK study, it is important to ensure that the concomitant antiretroviral drugs are fully virologically active when switching from a ritonavir boosted protease inhibitor to raltegravir as otherwise there is an increased risk for virological failure [41]. Elvitegravir, the other integrase inhibitor in current clinical development, is administered with the new developed CYP3A inhibitor GS9350 to reduce its first-pass metabolism and systemic clearance. As GS-9350 is more specific in the inhibition of CYP3A [63] compared to ritonavir-boosted HIV-protease inhibitors less pronounced drug-to-drug interactions may be expected with elvitegravir and $\mathrm{HCV}$ protease inhibitors or the immunosuppressant class of calcineurin inhibitors. Thus far however pharmacokinetic interaction studies are lacking.

\section{HAART in EnD-STAge Liver Disease}

Several antiretroviral drugs are extensively metabolized via the liver so that liver cirrhosis with liver insufficiency may pose these patients at particular risk for overdosing and hepatotoxicity. Indeed data on a prospective cohort of $231 \mathrm{HIV} / \mathrm{HCV}$-coinfected patients [22] with available liver histology who were followed for liver toxicity under a current HAART regimen showed that the adjusted rate of liver toxicity was higher in patients with cirrhosis compared with those without cirrhosis ( 25 vs $11 \%$, relative risk $2.23, \mathrm{p}=$ $0.06)$. Furthermore liver toxicity was more frequently observed in patients with Child Pugh Score B than in Score A groups (60 vs $18 \%$, relative risk 4.68, $\mathrm{p}=$ 0.04). Patients coinfected with chronic hepatitis and advanced stages of fibrosis should thus be carefully monitored for drug-related adverse events and pharmacokinetic monitoring may be justified in cases of suspected overdosing of antiretroviral drugs. Of the current available antiretroviral drugs enhanced toxicity due to high plasma drug levels in patients with advanced liver fibrosis has been described for the NNRTIs efavirenz $[9,10,64-66]$ and nevirapine $[9,23,67$, 68]. Current guidelines of the Department of Human 
Health Services (DHHS) recommend dose adjustments in case of liver insufficiency for fos-amprenavir and indinavir and provision of unboosted atazanavir without ritonavir in case of liver cirrhosis [69].

New antiretroviral drugs not metabolized primarily via the liver may be an attractive alternative for patients with decompensated liver disease or advanced stages of fibrosis. Raltegravir, similar to lamotrigine, phenprocoumon or naloxone, is metabolized in the liver solely via glucuronidation so that liver insufficiency is expected to have less pronounced effects on the metabolism of this drug compared to NNRTIs or PIs [70-72]. Given the broad therapeutic range of raltegravir no significant influence of hepatic insufficiency on the safety of raltegravir can be expected. Within the clinical development of raltegravir no significant effect of liver insufficiency (patients included with a CHILD-Pugh score 7 - 9) on the pharmacokinetic profile of Raltegravir was observed [36].

Liver transplantation in HIV-infected patients with $\mathrm{HCV}$ associated liver cirrhosis may place clinicians in a particular challenging situation as interactions between HAART, calcineurin-inhibitors and anti-HCV therapy have often to be managed simultaneously. New antiretroviral drugs offering less drug-to-drug interactions with cyclosprin A or tacrolimus would be desirable in order to facilitate post-transplant management of HIV-infected patients. As pointed out above raltegravir and S/GSK1349572 both have a low propensity to meaningfully affect the pharmacokinetics of coadministered drugs. Clinical data is available for raltegravir. which has shown no significant drug-to-drug interactions when administered to patients post liver or renal transplantation who received either sirolimus [73], tacrolimus or cyclosporine A [74].

\section{CONCLUSIONS}

HIV and HCV co-infected individuals benefit from early HAART due to slowed liver fibrosis progression under immune-reconstitution. The choice of antiretroviral agents is compromised in HCV co-infected patients due to an overall increased risk for hepatotoxicity and drugs with an inherent risk for liver transaminase elevations or mitochondrial toxicity should be avoided if possible. Interactions of antiretroviral drugs with ribavirin but also synergistic toxicity of some NRTIs with ribavirin in case of anti-HCV therapy further compromise the choice of NRTIs. Moreover, in cirrhotic patients liver insufficiency may complicate HIV therapy if drugs primarily metabolized via the liver are used and therapeutic drug monitoring and dose adjustments may be necessary in individual cases, in particular for the NNRTI efavirenz and some of the PIs such as Fosamprenavir. Current DHHS guidelines and prescribing information of the individual drug may help to assess the need for therapeutic drug monitoring and dose adjustment. Drug-to-drug interactions with new anti-HCV agents or immunosuppressants after liver transplantation are other potential problems to be encountered in clinical care that need to be addressed. New antiretroviral agents like the integrase inhibitors offer the opportunity to modify HAART for the duration of anti-HCV therapy to cir- cumvent interactions with ribavirin, or the new STAT$\mathrm{C}$ telaprevir and boceprevir.

Of the integrase inhibitors, raltegravir is currently the only licensed integrase inhibitor for the treatment of HIV-infection and has thus most clinical data available. In general, the safety profile of raltegravir in patients with hepatitis B and/or hepatitis C coinfection was similar to that in patients without hepatitis $B$ and/or hepatitis C coinfection. Raltegravir may be safely administered to patients with mild or moderate liver insufficiency and no significant drug to drug interactions are known with sirolimus, cyclosporine A or tacrolimus, immunosuppressant agents used after solid organ transplantation. Elvitegravir and S/GSK1349572, integrase inhibitors currently in clinical development, may constitute further treatment options in the setting of HIV and HCV co-infection. However, already now the class of integrase inhibitors offer great treatment alternatives in the setting of antiHCV therapy or liver transplantation.

\section{REFERENCES}

1. Mocroft A, Ledergerber B, Katlama C et al. Decline in the AIDS and death rates in the EuroSIDA study: an observational study. Lancet 2003; 362: 22-9.

2. Rosenthal E, Pialoux G, Bernard N et al. Liver-related mortality in human-immunodeficiency-virus-infected patients between 1995 and 2003 in the French GERMIVIC Joint Study Group Network (MORTAVIC 2003 Study). J Viral Hepat 2007; 14: 183-8.

3. Thein HH, Yi Q, Dore GJ et al. Natural history of hepatitis $\mathrm{C}$ virus infection in HIV-infected individuals and the impact of HIV in the era of highly active antiretroviral therapy: a meta-analysis. AIDS 2008; 22: 1979-91.

4. Arey B, Markov M, Ravi J et al. Nodular regenerative hyperplasia of liver as a consequence of ART. AIDS 2007; 21: 1066-8

5. Bani-Sadr F, Lapidus N, Bedossa P et al. Progression of fibrosis in HIV and hepatitis $\mathrm{C}$ virus-coinfected patients treated with interferon plus ribavirin-based therapy: analysis of risk factors. Clin Infect Dis 2008; 46: 768-74.

6. Mallet V, Blanchard P, Verkarre V et al. Nodular regenerative hyperplasia is a new cause of chronic liver disease in HIV-infected patients. AIDS 2007; 21: 187-92.

7. Sandrine PF, Sylvie A, Andre E et al. Nodular regenerative hyperplasia: a new serious antiretroviral drugs side effect? AIDS 2007; 21: 1498-9.

8. Rockstroh JK, Bhagani S, Benhamou Y et al. European AIDS Clinical Society (EACS) guidelines for the clinical management and treatment of chronic hepatitis $\mathrm{B}$ and $\mathrm{C} \mathrm{CO}-$ infection in HIV-infected adults. HIV Med 2008; 9: 82-8.

9. Barreiro P, Rodriguez-Novoa S, Labarga P et al. Influence of liver fibrosis stage on plasma levels of antiretroviral drugs in HIV-infected patients with chronic hepatitis C. J Infect Dis 2007; 195: 973-9.

10. Meynard JL, Lacombe K, Poirier JM et al. Influence of liver fibrosis stage on plasma levels of efavirenz in HIVinfected patients with chronic hepatitis B or C. J Antimicrob Chemother 2009; 63: 579-84.

11. Spagnuolo V, Gentilini G, De Bona A et al. Liver function parameters in $\mathrm{HIV} / \mathrm{HCV}$ co-infected patients treated with amprenavir and ritonavir and correlation with plasma levels. New Microbiol 2007; 30: 279-82.

12. Jain AK, Venkataramanan R, Shapiro R et al. The interaction between antiretroviral agents and tacrolimus in liver and kidney transplant patients. Liver Transpl 2002; 8: 841-5. 
13. Vogel M, Voigt E, Michaelis HC et al. Management of drug-to-drug interactions between cyclosporine $\mathrm{A}$ and the protease-inhibitor lopinavir/ritonavir in liver-transplanted HIV-infected patients. Liver Transpl 2004; 10: 939-44.

14. Kumar MS, Sierka DR, Damask AM et al. Safety and success of kidney transplantation and concomitant immunosuppression in HIV-positive patients. Kidney Int 2005; 67: 1622-9.

15. Vogel M, Rockstroh JK. Hepatotoxicity and liver disease in the context of HIV therapy. Curr Opin HIV AIDS 2007; 2: 306-13.

16. Aceti A, Pasquazzi C, Zechini B et al. Hepatotoxicity development during antiretroviral therapy containing protease inhibitors in patients with HIV: the role of hepatitis $\mathrm{B}$ and $\mathrm{C}$ virus infection. J Acquir Immune Defic Syndr 2002; 29: 41-8.

17. Bonfanti P, Landonio S, Ricci E et al. Risk factors for hepatotoxicity in patients treated with highly active antiretroviral therapy. J Acquir Immune Defic Syndr 2001; 27: 316-8

18. Servoss JC, Kitch DW, Andersen JW et al. Predictors of antiretroviral-related hepatotoxicity in the adult AIDS Clinical Trial Group (1989-1999). J Acquir Immune Defic Syndr 2006; 43: 320-3.

19. Rivero A, Mira JA, Pineda JA. Liver toxicity induced by non-nucleoside reverse transcriptase inhibitors. J Antimicrob Chemother 2007; 59: 342-6.

20. Torti C, Costarelli S, De Silvestri A et al. Analysis of severe hepatic events associated with nevirapine-containing regimens: CD4+ T-cell count and gender in hepatitis C seropositive and seronegative patients. Drug Saf 2007; 30: 1161-9.

21. van Leth F, Andrews S, Grinsztein B et al. The effect of baseline CD4 cell count and HIV-1 viral load on the efficacy and safety of nevirapine or efavirenz-based first-line HAART. AIDS 2005; 19: 463-71.

22. Casado J, Aranzabal L, Moya J et al. HAART-associated Hepatotoxicity in HIV/HCV-co-infected Patients with Cirrhosis. 13th Conference on Retroviruses and Opportunistic Infections. Denver, Colorado, USA, 2006; Abstract 889

23. Aranzabal L, Casado JL, Moya J et al. Influence of liver fibrosis on highly active antiretroviral therapy-associated hepatotoxicity in patients with HIV and hepatitis C virus coinfection. Clin Infect Dis 2005; 40: 588-93.

24. Leng K, Lonsdorf A, Hartmann M. Fatal outcome of nevirapine-associated toxic epidermal necrolysis. Int J STD AIDS 2008; 19: 642-3.

25. Maniar JK, Shah SR, Verma R et al. Nevirapine-induced fulminant hepatitis. J Assoc Physicians India 2006; 54: 957-8.

26. Bjornsson E, Olsson R. Suspected drug-induced liver fatalities reported to the WHO database. Dig Liver Dis 2006; 38: 33-8.

27. Serious adverse events attributed to nevirapine regimens for postexposure prophylaxis after HIV exposures-worldwide, 1997-2000. MMWR Morb Mortal Wkly Rep 2001; 49: 1153-6.

28. Lewis W, Dalakas MC. Mitochondrial toxicity of antiviral drugs. Nat Med 1995; 1: 417-22.

29. Clark SJ, Creighton S, Portmann B et al. Acute liver failure associated with antiretroviral treatment for HIV: a report of six cases. J Hepatol 2002; 36: 295-301.

30. Lichterfeld M, Fischer HP, Spengler U et al. [Fatty liver and increased serum lactate in a woman with HIV]. Dtsch Med Wochenschr 2003; 128: 81-4.

31. Puoti M, Torti C, Ripamonti D et al. Severe hepatotoxicity during combination antiretroviral treatment: incidence, liver histology, and outcome. J Acquir Immune Defic Syndr 2003; 32: 259-67.

32. Cornejo-Juarez P, Sierra-Madero J, Volkow-Fernandez P.
Metabolic acidosis and hepatic steatosis in two HIV-infected patients on stavudine (d4T) treatment. Arch Med Res 2003; 34: 64-9.

33. Laguno M, Milinkovic A, de Lazzari E et al. Incidence and risk factors for mitochondrial toxicity in treated HIV/HCV-coinfected patients. Antivir Ther 2005; 10: 423-9.

34. ter Hofstede HJ, de Marie S, Foudraine NA et al. Clinical features and risk factors of lactic acidosis following longterm antiretroviral therapy: 4 fatal cases. Int J STD AIDS 2000; 11: 611-6.

35. Vrouenraets SM, Treskes M, Regez RM et al. Hyperlactataemia in HIV-infected patients: the role of NRTI-treatment. Antivir Ther 2002; 7: 239-44.

36. Merck Research Laboratories, Merck \& Co. Inc. Food \& Drug Administration (FDA) Briefing Document (Background Package) on Isentress (raltegravir). Antiviral Drugs Advisory Committee Meeting, September 5, 2007 : http://www.fda.gov/ohrms/dockets/ac/07/briefing/ 2007-4314b1-01-Merck.pdf

37. Grinspoon S, Carr A. Cardiovascular risk and body-fat abnormalities in HIV-infected adults. N Engl J Med 2005; 352: 48-62.

38. Neuschwander-Tetri BA. Nonalcoholic steatohepatitis and the metabolic syndrome. Am J Med Sci 2005; 330: 326-35.

39. McGovern BH, Ditelberg JS, Taylor LE et al. Hepatic steatosis is associated with fibrosis, nucleoside analogue use, and hepatitis C virus genotype 3 infection in HIVseropositive patients. Clin Infect Dis 2006; 43: 365-72.

40. Sulkowski MS, Mehta SH, Torbenson M et al. Hepatic steatosis and antiretroviral drug use among adults coinfected with HIV and hepatitis C virus. Aids 2005; 19: 585-92.

41. Eron J, Andrade J, Zajdenverg R et al. Switching from Stable Lopinavir/Ritonavir-based to Raltegravir-based Combination ART Resulted in a Superior Lipid Profile at Week 12 but Did Not Demonstrate Non-Inferior Virologic Efficacy at Week 24. 16th Conference on Retroviruses and Opportunistic Infections. Montreal, Canada, 2009; Abstract 70aLB

42. Lennox J, Dejesus E, Lazzarin A et al. Safety and Efficacy of Raltegravir-Based Versus Efavirenz-Based Combination Therapy in Treatment-Naïve HIV-1 Infected Patients: STARTMRK Protocol 021. STARTMRK Protocol 021 48th Annual ICAAC / IDSA 46th Annual Meeting. Washington DC, USA, 2008; Abstract H-896a.

43. Steigbigel RT, Cooper DA, Kumar PN et al. Raltegravir with optimized background therapy for resistant HIV-1 infection. N Engl J Med 2008; 359: 339-54.

44. Steigbigel R, Cooper D, Eron J et al. 96-Week Results from BENCHMRK 1 and 2, Phase III Studies of Raltegravir in Patients Failing ART with Triple-class-resistant HIV. 16th Conference on Retroviruses and Opportunistic Infections. Montreal, Canada, 2009; Abstract 571b.

45. Merck \& Co. Inc. Prescribing information Isentress (raltegravir) tablets. Whitehouse Station, NJ, USA, 2009.

46. Mena A, Blanco F, Cordoba $\mathrm{M}$ et al. Hepatic safety profile of raltegravir in HIV patients with chronic hepatitis C. 5th IAS Conference on HIV Pathogenesis, Treatment and Prevention. Cape Town, South Africa, 2009; Abstract WEPEB230

47. Scourfield A, Waters LJ, Randell PA et al. Effect of raltegravir on ALT in subjects coinfected with HIV and hepatitis C. 15th Annual Conference of the British HIV Association. Liverpool, United Kingdom, 2009; Abstract P69.

48. Brau N, Salvatore M, Rios-Bedoya CF et al. Slower fibrosis progression in $\mathrm{HIV} / \mathrm{HCV}$-coinfected patients with successful HIV suppression using antiretroviral therapy. J Hepatol 2006; 44: 47-55. 
49. Pineda JA, Garcia-Garcia JA, Aguilar-Guisado M et al. Clinical progression of hepatitis $\mathrm{C}$ virus-related chronic liver disease in human immunodeficiency virus-infected patients undergoing highly active antiretroviral therapy. Hepatology 2007; 46: 622-30.

50. Bruno R, Sacchi P, Puoti M et al. Natural history of compensated viral cirrhosis in a cohort of patients with HIV infection. J Acquir Immune Defic Syndr 2007; 46: 297 303.

51. Schwabe RF, Bataller R, Brenner DA. Human hepatic stellate cells express CCR 5 and RANTES to induce proliferation and migration. Am J Physiol Gastrointest Liver Physiol 2003; 285: G949-58.

52. Hellier S, Frodsham AJ, Hennig BJ et al. Association of genetic variants of the chemokine receptor CCR5 and its ligands, RANTES and MCP-2, with outcome of HCV infection. Hepatology 2003; 38: 1468-76.

53. Bani-Sadr F, Carrat F, Pol S et al. Risk factors for symptomatic mitochondrial toxicity in HIV/hepatitis $\mathrm{C}$ viruscoinfected patients during interferon plus ribavirin-based therapy. J Acquir Immune Defic Syndr 2005; 40: 47-52.

54. Alvarez D, Dieterich DT, Brau N et al. Zidovudine use but not weight-based ribavirin dosing impacts anaemia during HCV treatment in HIV-infected persons. J Viral Hepat 2006; 13: 683-9.

55. Bani-Sadr F, Lapidus N, Melchior JC et al. Severe weight loss in HIV / HCV-coinfected patients treated with interferon plus ribavirin: incidence and risk factors. J Viral Hepat 2008; 15: 255-60.

56. Bani-Sadr F, Denoeud L, Morand P et al. Early virologic failure in HIV-coinfected hepatitis C patients treated with the peginterferon-ribavirin combination: does abacavir play a role? J Acquir Immune Defic Syndr 2007; 45: 123 5.

57. Vispo E, Barreiro P, Pineda JA et al. Low response to pegylated interferon plus ribavirin in HIV-infected patients with chronic hepatitis $\mathrm{C}$ treated with abacavir. Antivir Ther 2008; 13: 429-37.

58. Laufer N, Laguno M, Perez I et al. Abacavir does not influence the rate of virological response in HIV-HCVcoinfected patients treated with pegylated interferon and weight-adjusted ribavirin. Antivir Ther 2008; 13: 953-7.

59. Mira JA, Lopez-Cortes LF, Barreiro P et al. Efficacy of pegylated interferon plus ribavirin treatment in HIV/hepatitis $\mathrm{C}$ virus co-infected patients receiving abacavir plus lamivudine or tenofovir plus either lamivudine or emtricitabine as nucleoside analogue backbone. J Antimicrob Chemother 2008; 62: 1365-73.

60. Vogel M, Ahlenstiel G, Klausen G et al. The effect of nucleoside HAART on the treatment of chronic HCV infection. 5th IAS Conference on HIV Pathogenesis, Treatment and Prevention. Cape Town, South Africa, 2009; Abstract WEPEB235.

61. Iwamoto M, Kassahun K, Troyer MD et al. Lack of a pharmacokinetic effect of raltegravir on midazolam: in vitro/in vivo correlation. J Clin Pharmacol 2008; 48: 20914.

62. Min S, Song I, Borland J et al. Pharmacokinetics (PK) and safety in healthy subjects of S/GSK1349572, a next generation, once-daily HIV integrase-inhibitor (INI). 5th IAS Conference on HIV Pathogenesis, Treatment and Prevention. Cape Town, South Africa, 2009; Abstract WEPEA099.
63. Mathias A, Lee M, Callebaut C et al. GS-9350: A Pharmaco-enhancer without Anti-HIV Activity. 16th Conference on Retroviruses and Opportunistic Infections. Montreal, Canada, 2009; Abstract 40.

64. Bickel M, Stephan C, Rottmann C et al. Severe CNS sideeffect and persistent high efavirenz plasma levels in a patient with $\mathrm{HIV} / \mathrm{HCV}$ coinfection and liver cirrhosis. Scand J Infect Dis 2005; 37: 520-2.

65. Dominguez S, Peytavin G, Guiguet M et al. The HEPADOSE study: evaluation of protease inhibitors and non nucleoside analogue plasma concentrations in $\mathrm{HIV} / \mathrm{HCV}$ and HIV infected patients. 3rd Conference on HIV Pathogenesis and Treatment. Rio De Janeiro, Brazil, 2005; Abstract WePp0305.

66. Nijhawan AE, Zachary KC, Kwara A et al. Status epilepticus resulting from severe efavirenz toxicity in an HIVinfected patient. AIDS Read 2008; 18: 386-8, C3.

67. Almond LM, Boffito M, Hoggard PG et al. The relationship between nevirapine plasma concentrations and abnormal liver function tests. AIDS Res Hum Retroviruses 2004; 20: 716-22.

68. De Requena DG, Jimenez-Nacher I, Soriano V. Changes in nevirapine plasma concentrations over time and its relationship with liver enzyme elevations. AIDS Res Hum Retroviruses 2005; 21: 555-9.

69. Panel on Antiretroviral Guidelines for Adults and Adolescents. Guidelines for the use of antiretroviral agents in HIV-1-infected adults and adolescents. Department of Health and Human Services, 2008; 1-139.

70. Brennscheidt U, Brunnmuller U, Proppe D et al. Pharmacokinetics of tilidine and naloxone in patients with severe hepatic impairment. Arzneimittelforschung 2007; 57: $106-$ 11 .

71. Kitteringham NR, Bustgens L, Brundert E et al. The effect of liver cirrhosis on the pharmacokinetics of phenprocoumon. Eur J Clin Pharmacol 1984; 26: 65-70.

72. Marcellin P, de Bony F, Garret $C$ et al. Influence of cirrhosis on lamotrigine pharmacokinetics. $\mathrm{Br} \mathrm{J}$ Clin Pharmacol 2001; 51: 410-4.

73. Moreno A, Barcena R, Quereda C et al. Safe use of raltegravir and sirolimus in an HIV-infected patient with renal impairment after orthotopic liver transplantation. AIDS 2008; 22: 547-8.

74. Tricot L, Teicher E, Peytavin G et al. Safety and efficacy of raltegravir in HIV-infected transplant patients cotreated with immunosuppressive drugs. Am J Transplant 2009; 9: 1946-52.

Address for correspondence:

Dr. Mark Nelson

Dept. of HIV Medicine

Chelsea \& Westminster Hospital

London, UK

Tel.: $\quad+44-208-746-5610$

Fax: $\quad+44-208-746-8537$

E-mail: mark.nelson@chelwest.nhs.uk 